\title{
IMPLANTAÇÃO DO SISTEMA APPCC NA PRODUÇÃO DE QUEIJO TIPO MUÇARELA
}

\author{
Juliana Arvani Zaniolo
}

Graduanda do Curso de Engenharia de Alimentos da Universidade do Estado de Mato Grosso (julianaarvani@gmail.com) Barra do Bugres - Brasil

Recebido em: 08/09/2015 - Aprovado em: 14/11/2015 - Publicado em: 01/12/2015 DOI: http://dx.doi.org/10.18677/Enciclopedia_Biosfera_2015_173

\begin{abstract}
RESUMO
queijo tipo muçarela é um dos mais consumidos e apreciados. Devido ao consumo é preciso garantir a fabricação de um alimento seguro, que não traga danos à saúde do consumidor. Assim, a aplicação de um sistema como o APPCC se torna fundamental para a realização do controle de qualidade durante a produção. Objetivou-se então identificar e analisar PCCs na produção de queijo tipo muçarela para verificar interferentes e eliminar não conformidades. Foram definidos os PCCs no processo de elaboração do produto e realizadas análises microbiológicas de coliformes totais e termotolerantes, Staphylococcus aureus e Salmonella sp., para auxiliar na definição dos pontos e para verificar a eficiência do sistema. Também foram realizadas análises físico-químicas para conferir a qualidade da matéria-prima usada na elaboração do produto. Com os PCCs estabelecidos foi montado um mapa descritivo para ser seguido durante o monitoramento do sistema. Pode-se observar, a partir dos resultados, que o leite usado na produção possui boa qualidade físicoquímica. Verificou-se também que a implantação do sistema APPCC no laticínio reduziu a carga microbiana encontrada durante o processo e melhorou a qualidade da matéria-prima utilizada, mesmo em pouco tempo de funcionamento. Dessa forma, o uso do sistema APPCC como ferramenta de qualidade mostrou ser efetivo.
\end{abstract}

PALAVRAS-CHAVE: APPCC, controle de qualidade, derivado lácteo

\section{IMPLEMENTATION OF THE SYSTEM HACCP IN CHEESE MOZZARELLA PRODUCTION}

\begin{abstract}
The mozzarella type cheese is one of the most consumed and appreciated. Because of consumption we need to ensure the production of safe food, that does not bring damage to consumer health. Thus, the application of a system such as HACCP becomes essential to perform the quality control during production. Then aimed to identify and analyze PCCs in production to check interferences and eliminate nonconformities. PCCs have been defined in the manufacturing process of the type mozzarella cheese and performed microbiological analysis of total and fecal coliforms, Staphylococcus aureus and Salmonella sp., To assist in the definition of points and to check the system's efficiency. They were also carried out physicochemical analysis to check the quality of raw material used in the preparation of the product. With established PCCs was mounted a descriptive map to be followed during the monitoring of the system. It can be seen from the results that the milk used
\end{abstract}


in production has good physico-chemical quality. It was also found that the implementation of HACCP dairy plant, reduced microbial load encountered during the process and improved quality of the raw material used, even in short time of operation. Thus, the use of HACCP as quality tool shown to be effective.

KEYWORDS: HACCP, quality control, milk derivative

\section{INTRODUÇÃO}

As indústrias de laticínios, assim como as demais indústrias alimentícias, demonstram preocupação e apresentam algumas dificuldades com o controle de micro-organismos que possam causar riscos aos produtos elaborados e a saúde dos consumidores. O leite por sua vez, além de ser uma excelente fonte para a alimentação humana, por ser rico em lipídeos, proteínas e vitaminas, é um alimento que pode ser considerado um ótimo substrato para o desenvolvimento de microorganismos dos mais diversos tipos. Por isso, tem-se uma imensa atenção com a qualidade do leite utilizado, que serve como matéria-prima na elaboração de uma enorme variedade de produtos beneficiados por laticínios (ORDÓÑEZ et al., 2005; GUIMARÃES, 2012).

Entre os produtos derivados do leite, o queijo é um dos principais alimentos produzidos e consumidos no país. A variedade que se encontra no mercado é imensa, podendo-se encontrar produtos tanto de origem estrangeira como de origem nacional, sendo esse um mercado que vem apresentando um crescimento significativo durante os últimos anos (SEBRAE, 2008).

O queijo tipo muçarela é um dos mais consumidos, por ter aplicação em pratos culinários, devido à boa elasticidade que possui e também é um queijo rico em vitaminas (DUARTE et al., 2011). Devido ao alto consumo, deve-se ter uma preocupação com a qualidade e sanidade desse produto, visto que são muitos os consumidores que o adquirem.

O mercado consumidor quer ter a garantia de que os alimentos estejam isentos de contaminantes químicos, biológicos, físicos ou de qualquer outra substância que prejudique a saúde. Em razão disso, a busca pela segurança nos alimentos vem crescendo de maneira considerável (SOBRAL, 2010), por isso, é importante que as empresas adotem algum sistema eficaz para efetuar esse controle.

Aplicado como um método para auxiliar na prevenção de doenças veiculadas por alimentos, o sistema de Análise de Perigos e Pontos Críticos de Controle (APPCC) proporciona maior confiabilidade do produto ofertado aos consumidores, além de conferir mais qualidade aos produtos comercializados, sendo esta essencial para o público que vem se apresentando cada vez mais exigente com o que consome. Também é um importante método para evitar perdas relacionadas a problemas que possam ocorrer durante a produção, como contaminação, degradação e perecibilidade do produto (NICOLOSO, 2010).

Pensando na preocupação em oferecer produtos de qualidade e na importância das indústrias produzirem alimentos sadios e confiáveis, foi objetivado o presente estudo para averiguar as condições da fabricação de queijo tipo muçarela, verificar possíveis pontos críticos de controle na linha de produção e implantar o sistema APPCC em uma empresa de derivados lácteos. 


\section{MATERIAL E MÉTODOS}

A implantação do sistema APPCC foi realizada em um laticínio de pequeno porte localizado na cidade de Castanheira, MT. O laticínio trabalha regido pelas normas de inspeção estadual e tem a capacidade de processar até 100.000 litros de leite diariamente, porém, a produção varia de acordo com a época do ano. A produção de queijo tipo muçarela na época de estudo (janeiro a abril de 2015) foi de aproximadamente $3000 \mathrm{~kg} / \mathrm{dia}$.

\section{Qualidade do leite}

Para se obter um produto final de qualidade é preciso ter uma matéria-prima de qualidade, por isso, foram realizadas análises para verificar a qualidade do leite usado na fabricação do queijo tipo muçarela. As amostras foram coletadas do silo de armazenamento do laticínio (leite in natura) e após a saída do pasteurizador.

Foram realizadas duas coletas de leite para verificar a qualidade, com um intervalo de aproximadamente um mês, sendo a primeira coletada em fevereiro e a segunda no mês de março/2015.

As análises das amostras foram feitas no momento da coleta no Laboratório de Controle de Qualidade do próprio laticínio, conforme as metodologias propostas pelo Instituto ADOLFO LUTZ (2008) e pela Instrução Normativa oo 68 (BRASIL, 2006). Sendo:

- Análise de acidez em graus Dornic: foi realizada com o auxílio de um acidímetro Dornic contendo solução Dornic e indicador fenolftaleína até a viragem da coloração da amostra;

- Fosfatase alcalina: $10 \mathrm{~mL}$ de carbonato, aquecido a $37^{\circ} \mathrm{C}$ com $1 \mathrm{~mL}$ da amostra, por uma hora. Depois foi adicionado $1 \mathrm{~mL}$ da solução precipitante, e filtrado $5 \mathrm{~mL}$ para colocar $1 \mathrm{~mL}$ de sulfato de cobre. Pipetou-se $5 \mathrm{~mL}$ de carbonato de sódio a $8 \%$ e adicionado 2 gotas de solução CQC. Aplicou-se $5 \mathrm{~mL}$ de n-butanol e invertido o tubo, e comparado com a cor dos padrões para ver o resultado;

- Peroxidase: adicionando a amostra $2 \mathrm{~mL}$ de guaiacol a $1 \%$ e 3 gotas de peróxido de a $3 \%$, formação de halo cor salmão resultado positivo;

- Pesquisa de adição de neutralizante (hidróxido de sódio): adicionando $2 \mathrm{~mL}$ da amostra e $2 \mathrm{~mL}$ guaiacol a $1 \%$, o aparecimento de coloração salmão indica presença.

As análises de: densidade, temperatura e $\mathrm{pH}$, foram feitas por meio de um analisador de leite Master Classic da marca AKSO®. Já a determinação do índice crioscópico, foi realizada por um crioscópio eletrônico minilak da marca Entelbra ${ }^{\circledR}$.

\section{Identificação e avaliação de pontos críticos de controle do processo}

Analisando o fluxograma do processo de produção do queijo tipo muçarela, foi estabelecida uma tabela para determinação de PCCs e a partir dos pontos encontrados elaborou-se um mapa descritivo para o produto.

Os parâmetros de monitoramento, limites críticos, medidas de correção e a forma de verificação usados na construção do mapa descritivo, foram determinados a partir de uma sequência lógica dos sete princípios do sistema APPCC, recomendada pelo manual genérico de procedimentos para análise de perigos e pontos críticos de controle em indústria de produtos de origem animal (BRASIL, 1998). 
Os riscos foram analisados quanto a importância para a saúde pública e/ou a perda de qualidade do produto e sua integridade. Uma árvore decisória foi utilizada para determinar se a matéria-prima ou ingrediente utilizado na fabricação do produto ou alguma etapa do processo existia um PCC.

\section{Análises microbiológicas das amostras}

Para as análises microbiológicas, foram coletadas amostras de cada um dos pontos críticos de controle definidos, tanto da salmoura, da água, do leite e do queijo (linha de produção e produto pronto). Estas foram coletadas em recipientes esterilizados e acondicionados em caixa de isopor com gelo e transportadas para o Laboratório de Microbiologia da Universidade do Estado de Mato Grosso, na cidade de Barra do Bugres, MT.

Para cada ponto de coleta, foram adquiridas duas amostras sendo coletadas no dia 13 de fevereiro de 2015 (primeira coleta) e no dia 16 de março de 2015 (segunda coleta).

As análises microbiológicas foram realizadas segundo a metodologia proposta por SILVA et al. (2010a), foram analisadas amostras da água utilizada na produção, do leite in natura e pasteurizado, do queijo tipo muçarela antes e depois da salmoura, da salmoura e do queijo pronto para o consumo, sendo feitas análises de coliformes totais e termotolerantes, Staphylococcus aureus e Salmonella sp.

A determinação de coliformes foi feita pelo método do número mais provável (NMP), sendo inicialmente incubados em caldo Lauril na temperatura de $35^{\circ} \mathrm{C}$ por 48 horas. Os tubos considerados positivos foram semeados e incubados em caldo Verde Brilhante Bile $2 \%$ a $35^{\circ} \mathrm{C}$ e caldo EC a $45^{\circ} \mathrm{C}$, ambos incubados por 24 horas.

O método do NMP também foi usado para as análises de Staphylococcus aureus, no qual as amostras foram incubadas em meio Ágar Bair Parker a 35ㄷ por 48 horas e a confirmação feita pelo teste de coagulase. Para a determinação de Salmonella sp., realizou-se um pré-enriquecimento em caldo lactosado a $35^{\circ} \mathrm{C}$ por 24 horas, sendo posteriormente encaminhado para o enriquecimento seletivo em caldo Rappaport-Vassilidis e caldo Tetrationato a $35^{\circ} \mathrm{C}$ por 24 horas. Depois seguiuse para o plaqueamento diferencial em Ágar Xilose Lisina Desoxicolato a $35 \circ \mathrm{C}$ por 24 horas, sendo a confirmação feita por teste bioquímico e sorológico.Todos os procedimentos foram realizados em triplicata para todas as amostras.

\section{Capacitação dos colaboradores}

Depois de feitas as análises da primeira amostragem, realizou-se uma capacitação com os colaboradores do laticínio, instruindo-os de como devem ser seguidas as boas práticas de fabricação e a maneira correta de execução dos procedimentos padrão de higiene operacional, que são pré-requisitos fundamentais para o funcionamento do sistema APPCC, assim como o controle de tratamento da água usada na produção. Na capacitação, informou-se sobre o processo de implantação e como deveria ser feito o monitoramento do APPCC junto ao mapa descritivo, para que desse modo, pudessem dar continuidade na implantação. Dois funcionários ficaram responsáveis por fazer a verificação diária de todos os pontos críticos de controle definidos, realizando a ação corretiva quando necessária.

Também foi orientado aos proprietários do Laticínio a realização de acompanhamentos com especialistas nas propriedades leiteiras que entregam 0 produto a empresa, para que deste modo, garantam a qualidade da matéria-prima utilizada na elaboração dos produtos. 


\section{RESULTADOS E DISCUSSÃO}

\section{Análises físico-químicas do leite}

Os resultados das análises físico-químicas realizadas no leite in natura e pasteurizado estão representados na Tabela 1.

TABELA 1: Médias dos valores das análises físico-químicas para verificação da qualidade do leite in natura e pasteurizado.

\begin{tabular}{lll}
\hline \multicolumn{1}{c}{ Análises Físico-químicas } & Leite in natura & Leite Pasteurizado \\
\hline Densidade & $1,028 \mathrm{~g} / \mathrm{mL}$ & $1,030 \mathrm{~g} / \mathrm{mL}$ \\
Índice Crioscópico & $-0,503^{\circ} \mathrm{H}$ & $-0,511^{\circ} \mathrm{H}$ \\
Temperatura & $8^{\circ} \mathrm{C}$ & $33^{\circ} \mathrm{C}$ \\
$\mathrm{pH}$ & 6,4 & 6,4 \\
Acidez & $17^{\circ} \mathrm{D}$ & $17^{\circ} \mathrm{D}$ \\
Fosfatase Alcanila & Positiva & Negativa \\
Peroxidase & Positiva & Positiva \\
Adição de Hidróxido de Sódio & Negativo & Negativo \\
\hline
\end{tabular}

As análises de densidade, tanto para amostras de leite in natura quanto às de leite pasteurizado, encontram-se dentro dos padrões de densidade estabelecidos pela Instrução Normativa oㅡ 62, a qual estabelece a identidade e qualidade do leite, e determina que a densidade de ambos esteja entre $1,028 \mathrm{~g} / \mathrm{mL}$ e $1,034 \mathrm{~g} / \mathrm{mL}$ (BRASIL, 2011a). O leite pasteurizado apresentou uma densidade um pouco maior que a do leite in natura, isso se deve ao fato de que o leite ao passar pelo pasteurizador acaba perdendo uma quantia de água e gordura, o que consequentemente afeta a densidade.

O aquecimento durante a pasteurização, também interfere no índice crioscópico, como pode ser visualizado na Tabela 1, no qual o leite pasteurizado apresenta uma redução dos valores desses parâmetros em relação aos encontrados para o leite in natura.

Os valores do índice crioscópico de ambas as amostras de leite, exibiram resultados fora dos padrões da $I N$ no 62, que determina que estes encontrem-se entre $-0,530^{\circ} \mathrm{H}$ e $-0,550^{\circ} \mathrm{H}$ (BRASIL, 2011a). Segundo MENDES et al. (2010), esse resultado não indica fraude por adição de água quando a densidade encontra-se de acordo com a legislação. O que poderia ter causado essa alteração seria uma mudança na alimentação dos animais no período da coleta.

A temperatura do leite in natura, armazenado na empresa em silo refrigerado, apresentou-se um grau acima do que a legislação preconiza, o leite transportado e armazenado não deve ultrapassar os $7^{\circ} \mathrm{C}$ até ser pasteurizado e usado para consumo ou transformação de derivados lácteos (BRASIL, 2011a). Já a amostra de leite coletada na saída do pasteurizador, apontou uma temperatura de $33^{\circ} \mathrm{C}$, encontrando-se de acordo com a literatura próxima do ideal para a fabricação do queijo (EMBRAPA, 2005).

Os valores de $\mathrm{pH}$ de ambas as amostras foram de 6,4, sendo que a faixa de pH normal do leite é de 6,6 a 6,8 (ORDÓÑEZ et al., 2005). MARTINS et al. (2008), em seus estudos verificaram valores semelhantes, leite cru apresentou $\mathrm{pH}$ de $6,4 \mathrm{e}$ o pasteurizado pH de 6,7. Segundo CASTRO et al. (2014), o pH é um parâmetro importante para a qualidade de queijos, tanto para a coagulação como para 0 dessoragem do coágulo, podendo influenciar a textura do produto final. 
A determinação da acidez é uma das análises de maior importância em leite usado para fabricação de queijos, pois influencia na adição dos ingredientes, como coagulante e fermento lácteo. A legislação estabelece que esta deve estar entre $14^{\circ} \mathrm{D}$ e 18으. Nas amostras analisadas a acidez apresentou-se em acordo com o estabelecido pela legislação. MARTINS et al. (2008), ao avaliarem amostras de leite cru e pasteurizado, também obtiveram acidez de 17으 nas amostras analisadas.

Para verificar a eficiência da pasteurização foram realizados testes para identificar a presença e ausência das enzimas fosfatase alcalina e peroxidase, que se encontram naturalmente presentes no leite. A fosfatase alcalina é inativada na temperatura de pasteurização, enquanto que a peroxidase é uma enzima mais termorresistente ( $85^{\circ} \mathrm{C}$ por 20 segundos), não sendo inativada quando submetida à temperatura de pasteurização, por isso, são usadas para comprovar a eficácia desse processo (ORDÓÑEZ et al., 2005). A análise do leite in natura comprovou a existência da presença das enzimas neste. $O$ tratamento térmico atingiu o tempo e a temperatura desejados, pois as análises constataram a inativação da fosfatase alcalina e a presença da peroxidase.

A análise para verificação de fraude no leite apresentou resultado satisfatório, pois o resultado foi negativo. A análise de neutralizante como hidróxido de sódio, que é usado muitas vezes para mascarar a acidez do leite que se encontra em estado de deterioração, apresentou resultado negativo.

A análise da qualidade do leite demonstrou que a matéria-prima usada na fabricação do queijo tipo muçarela, encontrou-se quase que totalmente dentro dos padrões estabelecidos pela legislação, com exceção do índice crioscópico um pouco acima, não sendo determinado nenhum tipo de fraude que afete na qualidade do leite. Desta forma, com uma matéria-prima em boas condições é possível ter um maior rendimento da produção e fabricação de produtos de qualidade.

\section{Análises microbiológicas}

As análises microbiológicas servem como forma de verificação do funcionamento do sistema APPCC, podendo verificar a qualidade das condições de processamento do produto e é possível auxiliar na determinação dos pontos críticos de controle ao longo de um processo. Para a produção do queijo tipo muçarela foram realizadas análises de alguns micro-organismos que servem como indicadores de qualidade, os resultados destas estão apresentados nas Tabelas 2 e 3.

TABELA 2: Análises microbiológicas dos pontos críticos de controle, primeira coleta.

\begin{tabular}{|c|c|c|c|c|}
\hline $\begin{array}{l}\text { Micro- } \\
\text { organismos }\end{array}$ & $\begin{array}{l}\text { Coliformes } \\
\text { Totais }\end{array}$ & $\begin{array}{l}\text { Coliformes } \\
\text { Termotolerantes }\end{array}$ & $\begin{array}{l}\text { Staphylococcus } \\
\text { aureus }\end{array}$ & Salmonella sp. \\
\hline $\begin{array}{l}\text { Unidade } \\
\text { medida }\end{array}$ & NMP/g ou mL & NMP/g ou mL & NMP/g ou mL & $\begin{array}{l}\text { Ausente } \\
25 \mathrm{~g}\end{array}$ \\
\hline 1 & 3 & $<3,0$ & - & Ausente \\
\hline 2 & $>1100$ & 36 & 6,1 & Presente \\
\hline 3 & 43 & 3,0 & 3,0 & Ausente \\
\hline 4 & 11 & 11 & 9,2 & Ausente \\
\hline 5 & 6,1 & 9,2 & 3,6 & Ausente \\
\hline 6 & 36 & 15 & 3,0 & Ausente \\
\hline 7 & 43 & 11 & - & Ausente \\
\hline
\end{tabular}

Onde: 1 - Água; 2 - Leite in natura; 3 - Leite Pasteurizado; 4 - Queijo tipo muçarela antes da salmoura; 5 - Salmoura; 6 - Queijo tipo muçarela depois da salmoura; 7 - Queijo tipo muçarela pronto. 
TABELA 3: Análises microbiológicas dos pontos críticos de controle, segunda coleta.

\begin{tabular}{|c|c|c|c|c|}
\hline $\begin{array}{c}\text { Micro- } \\
\text { organismos }\end{array}$ & $\begin{array}{l}\text { Coliformes } \\
\text { Totais }\end{array}$ & $\begin{array}{c}\text { Coliformes } \\
\text { Termotolerantes }\end{array}$ & $\begin{array}{c}\text { Staphylococcus } \\
\text { aureus }\end{array}$ & Salmonella sp. \\
\hline $\begin{array}{l}\text { Unidade } \\
\text { medida }\end{array}$ & $\mathrm{NMP} / \mathrm{g}$ ou $\mathrm{mL}$ & NMP/g ou $\mathrm{mL}$ & NMP/g ou $\mathrm{mL}$ & $\begin{array}{l}\text { Ausente } \\
25 \mathrm{~g}\end{array}$ \\
\hline 1 & - & - & - & Ausente \\
\hline 2 & 75 & 15 & 3,0 & Ausente \\
\hline 3 & 3,6 & $<3,0$ & 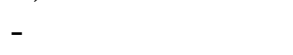 & Ausente \\
\hline 4 & $<3,0$ & $<3,0$ & - & Ausente \\
\hline 5 & - & - & - & Ausente \\
\hline 6 & 3,6 & 15 & - & Ausente \\
\hline 7 & 35 & 3,0 & - & Ausente \\
\hline
\end{tabular}

Os valores das análises microbiológicas da água utilizada no processo de fabricação do queijo tiveram diferença em relação ao período da coleta da amostra (antes e depois da implantação do sistema APPCC). Na Tabela 4, encontram-se os valores estabelecidos pela legislação para a qualidade microbiológica da água.

TABELA 4: Valores máximos estabelecidos pela legislação para água.

\begin{tabular}{lll}
\hline \multicolumn{1}{c}{ Micro-organismos } & \multicolumn{1}{c}{ Máximo } & Unidade de Medida \\
\hline Coliformes Totais & Ausente & Em $100 \mathrm{~mL}$ \\
Coliformes Termotolerantes & Ausente & Em $100 \mathrm{~mL}$ \\
Salmonella sp. & Ausente & Em $25 \mathrm{~g}$ \\
Staphylococcus aureus & Ausente & UFC/g ou mL \\
\hline
\end{tabular}

Fonte: Adaptado de BRASIL (2011b).

A água é extremamente utilizada na indústria de alimentos como veículo para aquecimento e resfriamento, limpeza, além de ingrediente ou meio para incorporar ingredientes. São necessários cuidados para manter a qualidade intacta, de modo que não cause contaminação ao longo da produção (SANDI, 2010). A Portaria no 2.914 de 12 de dezembro de 2011 do Ministério da Saúde (BRASIL, 2011b), estabelece que as análises microbiológicas de coliformes totais e termotolerantes apresentem ausência em $100 \mathrm{~mL}$ de amostra, e ausência para qualquer microorganismo patogênico, como Salmonella sp. e Staphylococcus aureus.

$\mathrm{Na}$ primeira amostra coletada, antes da implantação do sistema APPCC, os resultados encontrados não estão de acordo com a legislação para as análises de coliformes totais e termotolerantes, as quais apresentaram valores de $3 \mathrm{NMP} / \mathrm{mL} e<$ $3,0 \mathrm{NMP} / \mathrm{mL}$, respectivamente, portanto, são considerados não aceitáveis para água de consumo. As análises de Salmonella sp. e Staphylococcus aureus apresentaram ausência em $25 \mathrm{~g}$, conforme estabelecido pela legislação vigente.

Após o início da implantação do sistema APPCC, os valores se alteraram de acordo com o estabelecido pela portaria no 2.914 do Ministério da Saúde (BRASIL, 2011b). Essa mudança se deve a implantação do programa de controle de qualidade da água que passou a ser mais efetivo. 
Na legislação não estão previstas para o leite cru refrigerado análises para coliformes totais e termotolerantes, desta maneira, não há registro determinando valores limites que permitam avaliar o grau de contaminação do leite in natura por estes micro-organismos. Porém a redução na carga microbiana do leite in natura auxilia na pasteurização, visto que uma menor contagem de micro-organismos precisa ser inativada, facilitando e tornando a pasteurização mais eficiente.

As análises microbiológicas realizadas no leite in natura mostraram que ocorreu uma redução em relação aos valores da amostra, antes da introdução do sistema APPCC, em relação à amostra coletada após o início da implantação do sistema. Este fato indica que medidas para garantir uma matéria-prima com maior qualidade foram tomadas, por meio da orientação dos colaboradores e proprietários da empresa. Estes últimos passaram a realizar visitas periódicas, acompanhados de um médico veterinário, nas propriedades que apresentaram alterações indesejáveis no leite entregue no laticínio, com isso, foi possível ter mais controle sobre a qualidade da matéria-prima usada na fabricação do queijo tipo muçarela.

Segundo BARROS (2011) e SCHNEIDER et al. (2014), o acompanhamento da produção leiteira é um dos meios mais eficientes para a melhoria das características do leite, pois muitos produtores não tem acesso à informações técnicas que auxiliem com os cuidados necessários na ordenha. As visitas de orientação às propriedades servem de incentivo para os produtores, já que muitos laticínios pagam o leite, não apenas pela quantidade, mas pela qualidade do produto.

A Instrução Normativa $\mathrm{n} \cong$ 62 , do Ministério da Agricultura, Pecuária e Abastecimento (BRASIL, 2011a), estabelece os valores máximos permitidos para o leite pasteurizado tipo C, o quais estão representados na Tabela 5.

TABELA 5: Valores máximos estabelecidos pela legislação para leite pasteurizado.

\begin{tabular}{lll}
\hline \multicolumn{1}{c}{ Micro-organismos } & \multicolumn{1}{c}{ Máximo } & Unidade de Medida \\
\hline Coliformes Totais & 4 & $\mathrm{NMP} / \mathrm{g}$ ou $\mathrm{mL}$ \\
Coliformes Termotolerantes & 2 & $\mathrm{NMP} / \mathrm{g}$ ou mL \\
Salmonella sp. & Ausente & Em $25 \mathrm{~g}$ \\
Staphylococcus aureus & Ausente & UFC/g ou mL \\
\hline
\end{tabular}

Fonte:Adaptado de BRASIL (2011a).

O leite pasteurizado em ambas as coletas para análises microbiológicas coliformes totais e termotolerantes apresentou valores acima do estabelecido pela normativa. Já para as análises de Staphylococcus aureus e Salmonella sp., os resultados relataram ausência desses micro-organismos nas duas amostragens.

Conforme SILVA et al. (2010b), esses resultados elevados podem indicar problemas no processamento do leite que podem ser causados por falhas no binômio tempo $x$ temperatura da pasteurização, ou por contaminação pósprocessamento, através de higienização inadequada do equipamento e/ou tratamento térmico insuficiente para eliminação dos micro-organismos.

A introdução da implantação do sistema APPCC, ajudou na redução da carga microbiana do leite pasteurizado, porém ainda não foi suficiente para que os valores ficassem de acordo com o exigido pela normativa. É preciso realizar um monitoramento mais rigoroso nesta etapa. Não existe legislação específica que determina a qualidade microbiológica da salmoura, porém como é constituída em 
sua maioria por água, a condição dessa água deve estar de acordo com o que é estabelecido para o consumo humano.

Os resultados da primeira coleta apresentaram valores altos para a carga microbiana da salmoura, sendo de 6,1 NMP/mL para coliformes totais, 9,2 NMP/mL para coliformes termotolerantes, 3,6 NMP/mL para Staphylococcus aureus e ausência para Salmonella sp. Bortolon (2012), ao avaliar as condições das salmouras de laticínios, obteve valores $<3,0 \mathrm{NMP} / \mathrm{mL}$ para coliformes totais, $<3,0$ $\mathrm{NMP} / \mathrm{mL}$ para coliformes termotolerantes e ausência de Salmonella sp., ressaltando a importância da realização do controle microbiológico das salmouras para que não ocorra contaminação do produto. Esses resultados podem indicar que a água empregada na salmoura não estava recebendo o tratamento adequado.

Os resultados da segunda coleta indicaram que os valores da carga microbiana da salmoura passaram a estar de acordo com o que preconiza a legislação e todas as análises apresentaram resultados negativos para os microorganismos avaliados. Mudança essa, causada pelo maior cuidado com qualidade da água e da qualidade físico-química da salmoura, após a implantação do sistema APPCC na indústria.

As Portarias no 146 de 7 de março de 1996 e a nº 364 de 4 de setembro de 1997 do Ministério da Agricultura (BRASIL, 1996; BRASIL, 1997), estabelecem os limites microbianos do queijo tipo muçarela, os quais estão representados na Tabela 6.

TABELA 6: Valores máximos estabelecidos pela legislação para queijo tipo muçarela antes e depois da salmoura e para o queijo pronto.

\begin{tabular}{lll}
\hline \multicolumn{1}{c}{ Micro-organismos } & \multicolumn{1}{c}{ Máximo } & Unidade de Medida \\
\hline Coliformes Totais & 10000 & UFC/g ou mL \\
Coliformes Termotolerantes & 5000 & UFC/g ou mL \\
Salmonella sp. & Ausente & Em 25g \\
Staphylococcus aureus & 1000 & UFC/g ou mL \\
\hline
\end{tabular}

Fonte: Adaptado de BRASIL (1996) e BRASIL (1997).

Os resultados apresentados na primeira coleta (Tabela 2) mostram que todas as análises microbiológicas estão de acordo com o limite estabelecido pela legislação, para todos os pontos onde o queijo foi avaliado. GOLLO et al. (2003), avaliaram a presença de coliformes totais e termotolerantes no queijo muçarela antes e depois da salmoura, e os resultados encontraram-se dentro do limite exigido, o que segundo os autores indica que a pasteurização do leite foi eficiente.

Os valores das análises da primeira coleta para coliformes totais e termotolerantes da amostra do queijo depois da passagem pela salmoura, apesar de se encontrarem de acordo com a legislação, houve um aumento em relação aos valores encontrados para o queijo antes da salmoura, o que mostra uma possível contaminação pela passagem do queijo pelo tanque de salmoura, confirmando a possibilidade da salmoura estar contaminada.

A análise microbiológica de Salmonella sp. nas amostras de queijo mostrou a ausência do micro-organismo em ambas as amostras nos dois períodos onde foram coletadas.As amostras analisadas na segunda coleta apresentaram uma diminuição em relação aos valores encontrados de coliformes totais e termotolerantes e Staphylococcus aureus em comparação com a primeira coleta para o queijo tipo 
muçarela nas etapas antes e depois da salmoura e queijo pronto. Esses resultados reafirmam a importância da introdução da implantação do sistema APPCC.

Outro fator que pode ter contribuído para a redução da carga microbiana entre as coletas, foi a capacitação oferecida aos colaboradores, a qual reforçou a maneira correta de execução dos pré-requisitos requeridos pelo programa APPCC, que são a aplicação adequada das boas práticas de fabricação e dos procedimentos padrão de higiene operacional, que passaram a ter maior monitoração.

\section{Análise de perigos e pontos críticos de controle}

A determinação dos perigos e pontos críticos de controle apresentada no Quadro 1, mostra que foram encontrados quatro PCCs, sendo estes nas etapas de recepção do leite, pasteurização, adição dos ingredientes e salmoura. Dos pontos estabelecidos três se identificam como perigo biológico e apenas um como perigo químico.

QUADRO 1: Determinação de perigos e pontos críticos de controle do queijo tipo muçarela.

\begin{tabular}{|c|c|c|c|}
\hline Etapas do Processo & $\begin{array}{c}\text { Identificação do } \\
\text { perigo }\end{array}$ & $\begin{array}{l}\text { Medidas de } \\
\text { Controle }\end{array}$ & $\mathrm{PCC}$ \\
\hline \multirow[t]{2}{*}{ Recepção do leite } & Antibiótico (Q) & $\begin{array}{l}\text { Realização de } \\
\text { testes para } \\
\text { verificação da } \\
\text { presença de } \\
\text { antibiótico }\end{array}$ & Sim \\
\hline & $\begin{array}{l}\text { Micro-organismo } \\
\text { patogênico (B) }\end{array}$ & Pasteurização & Não \\
\hline \multirow[t]{2}{*}{ Resfriamento/Estocagem } & $\begin{array}{l}\text { Multiplicação de } \\
\text { micro-organismos } \\
\text { patogênicos (B) }\end{array}$ & Pasteurização & Não \\
\hline & Toxinas $(Q)$ & $\begin{array}{l}\text { Controle de } \\
\text { temperatura }\end{array}$ & Não \\
\hline Pasteurização & $\begin{array}{c}\text { Sobrevivência de } \\
\text { micro-organismos } \\
\text { patogênicos (B) }\end{array}$ & $\begin{array}{l}\text { Controle de tempo } \\
\text { e temperatura }\end{array}$ & $\operatorname{Sim}$ \\
\hline Adição dos ingredientes & $\begin{array}{c}\text { Contaminação de } \\
\text { micro-organismos } \\
\text { patogênicos (B) }\end{array}$ & $\begin{array}{c}\text { Programa prévio de } \\
\text { controle de } \\
\text { matéria-prima }\end{array}$ & $\operatorname{Sim}$ \\
\hline Coagulação & Não se identifica & *NA & $\mathrm{NA}$ \\
\hline $\begin{array}{c}\text { Aquecimento com agitação, } \\
\text { Dessoragem, filagem }\end{array}$ & Não se identifica & $\mathrm{NA}$ & NA \\
\hline Salmoura & $\begin{array}{l}\text { Contaminação de } \\
\text { micro-organismos } \\
\text { patogênicos (B) }\end{array}$ & $\begin{array}{l}\text { Análise da } \\
\text { salmoura }\end{array}$ & Sim \\
\hline Maturação e embalagem & Não se identifica & NA & NA \\
\hline
\end{tabular}

*NA: não se aplica. 
A etapa de recepção do leite representa um perigo químico, havendo a possibilidade de recebimento do leite de animais em tratamento, com resíduos de antibióticos. Os resíduos de antibióticos, quando presentes no leite, podem provocar uma diversidade de efeitos danosos à saúde da população e acarretar problemas na linha de processamento de derivados lácteos (MARTINS \& ANDRADE, 2011; SILVA et al., 2011). Uma alternativa para o controle deste perigo, além dos testes de detecção de antibióticos, é a realização de rastreabilidade da matéria-prima.

Conforme EGEA \& DENESI (2013), a recepção do leite determina um PCC, devido nesta etapa o leite in natura possuir uma microbiota natural e nutrientes suficientes para o desenvolvimento de micro-organismos, sendo necessária a realização de avaliações de cada lote de matéria-prima que chegue à indústria.

Na pasteurização foi determinado um perigo de natureza biológica, pois o leite in natura chega com elevada carga microbiana, e a pasteurização é a única forma de controlar esse risco, não havendo outra etapa subsequente efetiva para a eliminação de micro-organismos patogênicos. Diante disso, o controle do binômio tempo e temperatura se torna fundamental para uma eficaz pasteurização (ORDÓÑEZ et al., 2005; SILVA et al., 2011). Caso a carga microbiana não seja controlada, pode levar ao desenvolvimento de micro-organismos que causam doenças alimentares aos que o consumirem (ANDRADE et al., 2008).

Segundo GOLLO et al. (2003), a etapa de pasteurização do leite é um ponto crítico de controle, porque quando se analisa o processamento dos queijos, verificase que a pasteurização é a única etapa na qual ocorre a eliminação dos perigos microbiológicos. FREGONESE (2008) e SARMENTO (2011), também identificaram esta etapa com um ponto crítico de controle, ressaltando a importância de uma pasteurização eficiente, pois caso esta seja falha, pode ocorrer a sobrevivência de micro-organismos patogênicos que podem comprometer a produção.

O terceiro PCC identificado foi na etapa de adição dos ingredientes, onde o perigo encontrado é de origem biológica. De acordo com Rocha (2008), a falta de um controle da qualidade das matérias-primas acaba interferindo no rendimento do processo de fabricação. GUIMARÃES (2012), também determinou a etapa de adição dos ingredientes de queijos um ponto crítico de controle. Pois, a existência de um programa inicial de controle de matéria-prima é de extrema importância, tendo em vista que os ingredientes usados para a fabricação do queijo tipo muçarela, como por exemplo, o coalho e o fermento lácteo, podem conter perigos biológicos, que influenciam diretamente na qualidade do queijo produzido.

O quarto e último PCC definido foi a etapa da salmoura, sendo considerada crítica no processo. A mesma salmoura é utilizada por vários dias, o que acaba acumulando impurezas e gerando alterações nas suas características físicoquímicas, podendo propiciar maior sobrevivência ou multiplicação de microorganismos, vindo a influenciar tanto na qualidade da salmoura quanto na qualidade dos queijos que passam por ela (AMARAL et al., 1992; BORTOLON, 2012). Pelo fato da salmoura ser reutilizada por muitos dias há a necessidade de avalição periódica. Ainda mais por ser um ponto que não tem muita atenção, por não existir legislação específica para o controle e padrão de qualidade (BORTOLON, 2012).

Todos os PCCs foram acompanhados diariamente pelos responsáveis da monitorização do sistema APPCC na empresa, fazendo uso do mapa descritivo, apresentado no Quadro 2, que possui as informações necessárias para correções de eventuais desvios dos limites críticos no processo, e a forma adequada de monitoramento e verificação de cada etapa que possui um PCC. 
QUADRO 2: Mapa descritivo dos pontos críticos de controle do processamento de queijo tipo muçarela.

\begin{tabular}{|c|c|c|c|c|c|c|}
\hline PCC & Perigo & Ponto de Controle & Limite Crítico & Monitoramento & Ação Corretiva & Verificação \\
\hline $\begin{array}{l}\text { Recepção do } \\
\text { leite }\end{array}$ & $\begin{array}{l}\text { Resíduo de } \\
\text { antibiótico }\end{array}$ & $\begin{array}{l}\text { Teste de detecção de } \\
\text { resíduos }\end{array}$ & Ausência & $\begin{array}{l}\text { Teste de detecção de } \\
\text { antibiótico em todos } \\
\text { os caminhões }\end{array}$ & $\begin{array}{l}\text { Descarte adequado do } \\
\text { leite e comunicação } \\
\text { aos fornecedores }\end{array}$ & $\begin{array}{c}\text { Verificação da } \\
\text { técnica e da validade } \\
\text { dos kits }\end{array}$ \\
\hline Pasteurização & $\begin{array}{l}\text { Sobrevivência } \\
\text { de micro- } \\
\text { organismos } \\
\text { patogênicos }\end{array}$ & $\begin{array}{l}\text { Binômio: tempo e } \\
\text { temperatura }\end{array}$ & $\begin{array}{c}72 \text { a } 75^{\circ} \mathrm{C} \text { por } \\
15 \text { a } 10 \\
\text { segundos }\end{array}$ & $\begin{array}{c}\text { Inspeção do } \\
\text { marcador de } \\
\text { temperatura e tempo } \\
\text { de retenção do leite }\end{array}$ & $\begin{array}{l}\text { Ajuste de tempo e } \\
\text { temperatura }\end{array}$ & $\begin{array}{c}\text { Aferição de } \\
\text { equipamentos e } \\
\text { instrumentos; } \\
\text { pesquisa de } \\
\text { peroxidase e fosfatase }\end{array}$ \\
\hline $\begin{array}{c}\text { Adição de } \\
\text { ingredientes }\end{array}$ & $\begin{array}{l}\text { Presença de } \\
\text { micro- } \\
\text { organismos } \\
\text { patogênicos }\end{array}$ & $\begin{array}{c}\text { Programa de } \\
\text { controle de matéria- } \\
\text { prima }\end{array}$ & Ausência & $\begin{array}{l}\text { Fichas técnicas } \\
\text { apresentando } \\
\text { aspectos } \\
\text { microbiológicos }\end{array}$ & $\begin{array}{c}\text { Trocar o lote e/ou } \\
\text { fabricante }\end{array}$ & $\begin{array}{l}\text { Supervisão; auditoria; } \\
\text { fichas de controle }\end{array}$ \\
\hline Salmoura & $\begin{array}{l}\text { Presença de } \\
\text { micro- } \\
\text { organismos } \\
\text { patogênicos }\end{array}$ & $\begin{array}{l}\text { Controle de acidez e } \\
\text { pH; controle } \\
\text { microbiológico }\end{array}$ & $\begin{array}{l}\mathrm{pH} \text { entre } 5,0 \mathrm{e} \\
5,4 ; \text { acidez } \\
\text { Dornic entre } \\
15 \text { e } 30^{\circ} \mathrm{D} ; \\
\text { mínimo } 18^{\circ} \mathrm{Bé}\end{array}$ & $\begin{array}{c}\text { Análise de } \mathrm{pH}, \\
\text { acidez e teor de sal; } \\
\text { controle de qualidade } \\
\text { da água }\end{array}$ & $\begin{array}{l}\text { Refazer a etapa; } \\
\text { correção da acidez }\end{array}$ & $\begin{array}{l}\text { Auditoria; aferição de } \\
\text { equipamentos; } \\
\text { aferição de curva de } \\
\text { equilibrio; programa } \\
\text { de coleta de amostras } \\
\text { para análise }\end{array}$ \\
\hline
\end{tabular}

O sistema APPCC apresentou ter êxito durante o tempo de acompanhamento. Porém, para que ele seja implantado com real funcionamento, ainda deve levar algum tempo para que aconteça. Mas diante do apresentado, estima-se que esteja funcionando de forma eficaz dentro de alguns meses.

\section{CONCLUSÃO}

A qualidade físico-química da matéria-prima utilizada para a fabricação dos queijos, como pode-se perceber, encontra-se praticamente dentro dos padrões estabelecidos pela legislação vigente, o que contribui para a produção de produtos de qualidade.

Os resultados das análises microbiológicas realizadas na água, no leite in natura e pasteurizado, nos queijos antes e depois de passagem pela salmoura, na salmoura e no produto pronto, mostraram que houve uma redução na carga microbiana após a implantação do sistema APPCC, deixando todos os pontos dentro do limite determinado.

Quatro pontos críticos de controle foram definidos ao longo da produção, os quais encontram-se na recepção do leite, na pasteurização, na adição de ingredientes e na salmoura. Após serem determinados, passou-se a ser realizado 0 monitoramento por meio do mapa descritivo elaborado de acordo com cada ponto.

A implantação do sistema APPCC na empresa estudada demonstrou ser eficiente para a elaboração de produtos de qualidade e sadios, sendo uma ferramenta da qualidade eficaz para a diminuição de riscos que possam vir a surgir 
no decorrer da produção, porém o sistema ainda encontra-se em fase de implantação o que pode levar de um a dois anos para que sua consolidação seja estabelecida na empresa.

\section{REFERÊNCIAS}

AMARAL, L. A.; NADER FILHO, A.; IARIA, S. T.; FERRO, J. A. Variação das características físico-químicas e microbiológicas das salmouras empregadas na salga de queijos tipo mussarela durante o período de sua utilização. Revista Saúde Pública, São Paulo, v. 26, n. 1, p. 41 - 45, 1992.

ANDRADE, P. V. D.; SOUZA, M. R.; PENNA, C. F. A. M.; FERREIRA, J. M. Características microbiológicas e físico-químicas do leite de cabra submetido à pasteurização lenta pós-envase e ao congelamento. Ciência Rural, Santa Maria, v. 38, n. 5, p. $1424-1430,2008$.

BARROS, R. A. Produção familiar de leite e de saber: a extensão rural no controle da mastite e qualidade do leite na APA Coqueiral, MG. 170 f. 2011. Dissertação (Mestrado em Ciências Veterinárias), Universidade Federal de Lavras, Lavras - MG, 2011.

BORTOLON, E. Avaliação da qualidade de salmouras empregadas na salga de queijos de laticínios inscritos no serviço de inspeção do Paraná (SIP) na microrregião de Francisco Beltrão - PR. 2012. 36 f. Trabalho de conclusão de curso (Graduação em Tecnologia de alimentos) - Curso Superior de Tecnologia de Alimentos, Universidade Tecnológica Federal do Paraná, Francisco Beltrão, 2012.

BRASIL. Ministério da Agricultura, do Abastecimento e da Reforma Agrária. Portaria n. 146 de 07 de março de 1996. Regulamento Técnicos de Identidade e Qualidade dos Produtos Lácteos. Diário Oficial da União, seção 1, Brasília, de 11 de março de 1996.

BRASIL. Ministério da Agricultura e do Abastecimento. Portaria n. 364 de 04 de setembro de 1997. Regulamento Técnico para Fixação de Identidade e Qualidade de Queijo Mozzarela. Diário Oficial da União, seção 1, Brasília, de 08 de setembro de 1997.

BRASIL. Ministério da Agricultura, Pecuária e Abastecimento. Portaria n. 46, de 10 de fevereiro de 1998. Manual genérico de procedimento para análise de perigos e pontos críticos de controle em indústrias de produtos de origem animal. Diário Oficial da União, seção 1, Brasília, 13 de março de 1998.

BRASIL. Ministério da Agricultura, Pecuária e Abastecimento. Instrução normativa n.68, de 12 de dezembro de 2006. Métodos Analíticos Oficiais Físico-Químicos para Controle de Leite e Produtos Lácteos. Diário Oficial da União, seção 1, Brasília, de 14 de dezembro de 2006.

BRASIL. Ministério da Agricultura, Pecuária e Abastecimento. Instrução normativa n. 62, de 29 de dezembro de 2011. Regulamento Técnico de Produção, Identidade e 
Qualidade do Leite tipo A, o Regulamento Técnico de Identidade e Qualidade de Leite Cru Refrigerado, o Regulamento Técnico de Identidade e Qualidade de Leite Pasteurizado e o Regulamento Técnico da Coleta de Leite Cru Refrigerado e seu Transporte a Granel. Diário Oficial da União, seção 1, Brasília, 30 de dezembro de 2011a.

BRASIL. Ministério da Saúde. Portaria n. 2.914 de 12 de dezembro de 2011. Procedimentos de controle e de vigilância da qualidade da água para consumo humano e seu padrão de potabilidade. Diário Oficial da União, seção 1, Brasília, de 14 de dezembro de 2011b.

CASTRO, K. A.; SILVA, K. A. L.; PEREIRA, A. I. A.; ORSINE, V. C. Efeito da contagem de células somáticas sobre a qualidade dos queijos prato e mussarela. Revista Brasileira de Tecnologia Agroindustrial, Ponta Grossa - PR, v. 8, n. 1, p. 1237 - 1250, 2014.

DUARTE, T. S.; BARBOSA, L. P. J. L.; BARBOSA, F. H. F. Avaliação microbiológica para determinação de Staphylococcus aureus em quatro marcas de queijos tipo mussarela comercializadas no município de Luz, Minas Gerais. Ciência Equatorial, v. 1, n. 1, 2011.

EGEA, M. B.; DANESI, E. D. G. Elaboração de APPCC no processamento de requeijão cremoso. Revista Tecnológica, Maringá, v. 22, p. 93 - 108, 2013.

Empresa Brasileira de Pesquisa Agropecuária - EMBRAPA. Queijo Mussarela. Coleção agroindústria familiar. Brasília, 2005.

FREGONESE, C. Elaboração do plano APPCC para linha de produção de leite fluido pasteurizado. 2008. 68 f. Trabalho de conclusão de curso (Obtenção do título de especialista em Higiene e Inspeção de Produtos de Origem Animal e Vigilância Sanitária), Universidade Castelo Branco, Curitiba, 2008.

GOLLO, R.; CANSIAN, R. L.; VALDUGA, E. Identificação de alguns pontos críticos de controle no processamento dos queijos prato e mussarela. Brazilian Journal of Food Technology, Campinas, v. 6, n. 1, p. $43-51,2003$.

GUIMARÃES, T. G. Determinação de pontos críticos de controle (PCC'S) em indústria de laticínios. 2012. 67 f. Trabalho de Conclusão de Curso (Graduação em Medicina Veterinária) - Faculdade de Veterinária, Universidade Federal do Rio Grande do Sul, Porto Alegre, 2012.

INSTITUTO ADOLFO LUTZ. Métodos físico-químicos para análise de alimentos. Instituto Adolfo Lutz. São Paulo, 2008.

MARTINS, A. M. C. V.; ROSSI JUNIOR, O. D.; SALOTTI, B. M.; BÜRGER, K. P.; CORTEZ, A. L. L.; CARDOSO, M. V. Efeito do processamento UAT (Ultra Alta Temperatura) sobre as características físico-químicas do leite. Ciências e Tecnologia de Alimentos, Campinas, v. 28, n. 2, p. 295 - 298, 2008. 
MARTINS, P. F.; ANDRADE, H. V. Identificação de resíduos de antibióticos na recepção de leite cru pré-beneficiado como perigo potencial para implantação do plano APPCC em laticínios. FAZU em revista, Uberaba, n. 8, p. 108 - 114, 2011.

MENDES, C. G.; SAKAMOTO, S. M.; SILVA, J. B. A.; JÁCOME, C. G. M.; LEITE, A. I. Análises físico-químicas e pesquisa de fraude no leite informal comercializado no município de Mossoró, RN. Ciência Animal Brasileira, Goiânia, v. 11, n. 2, p. 349 356, 2010.

NICOLOSO, T. F. Proposta de integração entre BPF, APPCC, PAS 220:2008 e a NBR ISSO 22000:2006 para indústria de alimentos. 2010. $70 \mathrm{f}$. Dissertação (Mestrado em Engenharia de Produto) - Centro de Tecnologia, Universidade Federal de Santa Maria, Santa Maria, 2010.

ORDÓÑEZ, J. P. et al. Tecnologia de Alimentos: Alimentos de Origem Animal. v. 2, Porto Alegre: Artmed, 2005.

SANDI, A. L. S. Diagnóstico de pontos críticos de contaminação microbiológica em uma agroindústria pedagógica. 103 f. 2010. Tese (Doutorado em Ciências dos Alimentos), Universidade Federal de Lavras, Lavras - MG, 2010.

SARMENTO, P. G. C. Implantação de um sistema de segurança alimentar (HACCP) numa indústria de produção de iogurte batido com pedaços de ananás e a validação do sistema. 2011. 162 f. Dissertação (Mestrado em Tecnologia e Segurança Alimentar) - Faculdade de Ciências e Tecnologia, Universidade Nova de Lisboa, Lisboa, 2011.

Serviço Brasileiro de Apoio às Micro e Pequenas Empresas - SEBRAE. Queijos nacionais: relatório completo. Série mercado, set., 2008.

SCHNEIDER, C. R.; ZAMBOM, M. A.; DESSBESELL, J. G.; TININI, R. C. R.; POZZA, M. S. S.; MILANEZE, H. S.; CORBARI, F.; HOELSCHER, G. L.; BERGMANN, J.; GARCIAS, J. FÜLBER, V. M. Acompanhamento da qualidade higiênico-sanitário de leite em propriedades agroecológicas de Diamante d'Oeste PR. Cadernos de Agroecologia, v. 9, n. 1, 2014.

SILVA, N.; JUNQUEIRA, V. C. A.; SILVEIRA, N. F. A.; TANIWAKI, M. H.; SANTOS, R. F. S.; GOMES, R. A. R. Manual de métodos de análise microbiológica de alimentos e água. 4. Ed. São Paulo: Livraria Varela, 2010a.

SILVA, V. A.; RIVAS, P. M.; ZANELA, M. B.; PINTO, A. T.; RIBEIRO, M. R.; SILVA, F. P.; MACHADO, M. Avaliação da qualidade físico-química e microbiológica do leite cru, do leite pasteurizado tipo $A$ e de pontos de contaminação de uma granja leiteira no RS. Acta Scientiae Veterinariae, Porto Alegre, v. 38, n. 1, p. 51 - 57, $2010 \mathrm{~b}$.

SILVA, J. N.; SOUZA, F. C.; PARENTE, G. D. L.; SILVA, L. M. M.; ALVEZ, T. T. L. Avaliação da eficiência da pasteurização em leite tipo $c$ através de parâmetros enzimáticos. Revista Verde, Mossoró - RN, v. 6, n. 3, p. 06 - 09, 2011.

SOBRAL, S. R. Boas Práticas e Procedimento Padrão de Higiene Operacional. SENAI, Brasília, 2010. 